\title{
Mild chronic kidney dysfunction and treatment strategies for stable coronary artery disease
}

Neuza Helena Lopes, MD, PhD, Felipe da Silva Paulitsch, MD, Alexandre Pereira, MD, PhD, Cibele Larossa Garzillo, MD, João Fernando Ferreira, MD, PhD, Noedir Stolf, MD, PhD, and Whady Hueb, MD, PhD

Objective: Our objective was to evaluate the association of chronic kidney dysfunction in patients with multivessel chronic coronary artery disease, preserved left ventricular function, and the possible interaction between received treatment and cardiovascular events.

Methods: The glomerular filtration rate was determined at baseline on 611 patients who were randomized into three treatment groups: medical treatment, percutaneous coronary intervention, and coronary artery bypass surgery. Incidence of myocardial infarction, angina requiring a new revascularization procedure, and death were analyzed during 5 years in each group.

Results: Of 611 patients, $112(18 \%)$ were classified as having normal renal function, 349 (57\%) were classified as having mild dysfunction, and $150(25 \%)$ were classified as having moderate dysfunction. There were significant differences among the cumulative overall mortality curves among the three renal function groups. Death was observed more frequently in the moderate dysfunction group than the other two groups $(P<.001)$. Interestingly, in patients with mild chronic kidney dysfunction, we observed that coronary artery bypass treatment presented a statistically higher percentage of event-free survival and lower percentage of mortality than did percutaneous coronary intervention or medical treatment

Conclusions: Our results confirm that coronary artery disease accompanied by chronic kidney dysfunction has a worse prognosis, regardless of the therapeutic strategy for coronary artery disease, when renal function is at least mildly impaired. Additionally, our data suggest that the different treatment strategies available for stable coronary artery disease may have differential beneficial effects according to the range of glomerular filtration rate strata.

Chronic kidney disease (CKD) is strongly associated with a higher risk of cardiovascular disease on presentation, and the presence of CKD is a potent predictor of a worse prognosis among patients with already established coronary artery disease $(\mathrm{CAD}){ }^{1-4}$ Studies have shown that at least $25 \%$ of the patients in dialysis had $\mathrm{CAD}^{5-7}$ and $10 \%$ had a previous myocardial infarction (MI). ${ }^{6}$ Adverse outcomes occur more often in end-stage CKD, and a higher risk of complications after revascularization procedures, percutaneous coronary intervention (PCI), or coronary artery bypass grafting (CABG) is present in these patients. ${ }^{8,9}$ More recently, even earlier stages of CKD have been associated with worse outcomes in patients with CAD. ${ }^{10,11}$ However, limited information exists regarding the interaction between different treatment options for chronic CAD and mild renal dysfunction.

\footnotetext{
From the Heart Institute (InCor), University of São Paulo Medical School, São Paulo, Brazil.

Clinical Trial Registration Information: ISRCTN66068876-The Medicine, Angioplasty, or Surgery Study: a randomized controlled clinical trial of three therapeutic strategies for multivessel coronary artery disease.

None of the authors has any conflict of interest.

Received for publication July 24, 2008; revisions received Oct 21, 2008; accepted for publication Nov 19, 2008.

Address for reprints: Neuza Helena Lopes, MD, PhD, Av D. Enéas de Carvalho Aguiar \# 44, sala 114. Cerqueira Cesar, São Paulo-SP/ Brazil 05403-000 (E-mail: mass@ incor.usp.br).

J Thorac Cardiovasc Surg 2009;137:1443-9

$0022-5223 / \$ 36.00$

Copyright (C) 2009 by The American Association for Thoracic Surgery

doi:10.1016/j.jtcvs.2008.11.028
}

To our knowledge, no randomized trial has compared the long-term clinical effect of medical treatment (MT) versus PCI or CABG in patients with mild or moderate renal dysfunction who have multivessel disease. We, therefore, explored the effect of mild or moderate CKD on the clinical outcomes of patients enrolled in the Medical, Angioplasty or Surgery Study (MASS II), comparing the impact of the three therapeutic option strategies in patients with symptomatic multivessel CAD stratified by CKD level.

\section{METHODS}

\section{Study Design and Patients}

This post hoc analysis used data from a previously conducted randomized trial and was approved by the Ethics Committee of the Heart Institute of the University of São Paulo Medical School. MASS II, a randomized trial that evaluated the long-term relative efficacies of three possible therapeutic strategies for patients with multivessel CAD, stable angina, and preserved left ventricular function, was described previously. ${ }^{12}$ In brief, 611 patients have given written, informed consent and were randomly assigned to MT $(\mathrm{n}=203)$, PCI $(\mathrm{n}=205)$, or CABG $(\mathrm{n}=203)$ if there was agreement on the part of the surgeon, attending physicians, and interventional cardiologists that revascularization could be attained by either strategy. All patients had angiographicaly documented proximal multivessel coronary stenosis of more than $70 \%$ by visual assessment and documented ischemia, defined by either stress testing or typical stable angina assessment of the Canadian Cardiovascular Society (class II or III).

Exclusion criteria included unstable angina or acute MI necessitating emergency revascularization, ventricular aneurysm necessitating surgical repair, left ventricular ejection fraction of less than $40 \%$, a history of PCI or CABG, single-vessel disease, or previous cardiac surgery. Patients were also excluded if they were unable to understand or cooperate with 


$\begin{aligned} & \text { Abbreviations and Acronyms } \\ & \text { APPROACH = } \text { Alberta Provincial Project for } \\ & \text { Outcomes Assessment in Coronary } \\ & \text { Heart Disease } \\ &= \text { coronary artery bypass grafting } \\ &= \text { coronary artery disease } \\ &= \text { confidence interval } \\ & \text { CABG } \text { chronic kidney dysfunction } \\ & \text { CAD } \text { estimated glomerular filtration rate } \\ & \text { CI }=\text { high-density lipoprotein } \\ & \text { CKD } \text { Medicine, Angioplasty, or } \\ & \text { eGFR } \text { Surgery Study } \\ & \text { HDL } \text { Modification of Diet in } \\ & \text { MASS II } \text { Renal Disease } \\ & \text { MDRD } \text { myocardial infarction } \\ & \text { MI } \text { medical treatment } \\ & \text { MT } \text { National Kidney Foundation } \\ & \text { NKF } \text { percutaneous coronary intervention } \\ & \text { PCI } \text { Results of Prevention of } \\ & \text { PRESTO } \text { REStenosis with Tranilast and } \\ & \text { its Outcomes } \\ & \text { RF }=\text { renal function } \\ & \text { RR } \text { relative risk }\end{aligned}$

the protocol requirements or to return for follow-up. By original study design, patients with end-stage CKD were not included in this study.

\section{Treatment Intervention}

All patients were placed on an optimal regimen consisting of a steppedcare approach using nitrates, aspirin, beta-blockers, calcium channel blockers, angiotensin-converting enzyme inhibitors, or a combination of these drugs, unless contraindicated. Lipid-lowering agents, particularly statins, were also prescribed, along with a low-fat diet, on an individual basis. Patients were then randomized to continue with aggressive MT alone or to undergo PCI or CABG concurrently with MT.

Requirements were to perform optimum coronary revascularization in accordance with current best practices. Equivalent anatomic revascularization was encouraged but not mandatory. For patients assigned to PCI, the procedures were performed within 3 weeks after randomization. Multivessel PCI was performed in $73 \%$ of the patients. Immediate angiographic success was achieved in $92 \%$ of patients in whom it was attempted, and $72 \%$ of them received at least one stent ( $62 \%$ received two or more stents). Complete revascularization was achieved in $41 \%$ of patients treated. Glycoprotein IIb/IIIa agents were not used. For patients assigned to CABG, the procedures were performed within 12 weeks after randomization. Complete resvacularization was accomplished in $74 \%$ of the patients. At least one internal thoracic artery was used for grafting in $92 \%$ of the cases. No offpump CABG was performed.

\section{Baseline Measurement of Renal Function}

All patients obtained the last single serum creatinine immediately before randomization. We estimated the glomerular filtration rate (eGFR) based on the Modification of Diet in Renal Disease (MDRD) study equation, as suggested by the National Kidney Foundation (NKF) guidelines. ${ }^{13}$ The MDRD formula is as follows: eGFR $\left(\mathrm{mL} / \mathrm{min}\right.$ per $\left.1.73 \mathrm{~m}^{2}\right)=(186 \times$ [Serum Creatinine $]^{-1.154}[\mathrm{mg} / \mathrm{dL}] \times$ age $[$ in years] $)$. The product of this equation was multiplied by a correction factor of 0.742 in women and 1.210 in African Brazilian patients. Patients were categorized in normal renal function (RF) and mild or moderate CKD groups depending on their eGFR $(\geq 90$, $90-60$, and $59-30 \mathrm{~mL} / \mathrm{min}$ per $1.73 \mathrm{~m}^{2}$, respectively), based on the National Kidney Foundation (NFK) classification.

\section{Study Outcomes}

Adverse and other clinical events were tracked from randomization. Patients were assessed with follow-up visits every 6 months for 5 years at the Heart Institute, University of São Paulo Medical School. Angina was considered refractory only when patients had been treated with full anti-ischemic therapies to their level of tolerance. MI was defined as the presence of significant new $\mathrm{Q}$ waves in at least two electrocardiographic leads or symptoms compatible with MI associated with creatine kinase MB fraction concentrations that were more than 3 times the upper limit of the reference range. Stroke was defined as the presence of neurologic clinical symptoms compatible with an episode of cerebrovascular ischemia associated with a computed tomographic image compatible with neurologic infarction.

The pre-defined primary end point for this study was the incidence of any-cause mortality, MI, refractory angina requiring revascularization, or stroke. All patients in the PCI group had routine planned angiograms at 6 months. These angiograms were not considered an end point-associated event because they were done independently of symptoms. Therapeutic $\mathrm{PCI}$ or $\mathrm{CABG}$ performed during an episode of unstable angina at any time during follow-up was considered an end-point event and was applied equally across all three arms of therapy.

\section{Statistical Analyses}

Continuous variables were estimated as the mean value \pm SD. Discrete variables were expressed as counts and percent values. Baseline clinical and demographic variables were compared across RF categories with the Kruskal-Wallis test followed by the Dunn test for multiple analyses for continuous variables and $\chi^{2}$ for categorical variables. The event-free survival time was defined as the interval between random assignment of treatment and the occurrence of one of the primary end points or the latest follow-up visit. Eventfree survival was estimated by the Kaplan-Meier method, and differences among groups were assessed by the log-rank test. eGRF was analyzed as a continuous value for the prediction of primary end points in univariate analyses. Potential independent predictors of outcome were identified by univariate analyses for each RF group by Cox proportional hazard analyses. Then, multivariate Cox proportional hazard survival analyses were performed to assess whether the associations of RF groups with all-cause mortality and combined end points were independent of potential confounders. Results are described as relative risks (RR; hazard ratio) with $95 \%$ confidence intervals (CI). All analyses were based on the intention-to-treat principle, and statistical tests were 2 tailed. Statistical analysis was performed with the Statistical Analysis System 6.14 software (SAS Institute, Inc, Cary, NC).

\section{RESULTS \\ Baseline Variables}

In the study population of $611,112(18 \%)$ patients were classified as having normal RF, $349(57 \%)$ were classified as having mild CKD, and $150(25 \%)$ were classified as having moderate CKD. Treatment assigned and baseline characteristics were similar among RF groups, except by age, smoking, body mass index, number of diseased vessels, tryglicerides, and high-density lipoprotein (HDL) cholesterol levels. The mild RF group more often were smokers, overweight, and had triple-vessel disease. On the other hand, across worsening RF categories, patients were older and more likely to have lower tryglicerides and higher HDL 
TABLE 1. Baseline characteristics by renal function group

\begin{tabular}{|c|c|c|c|c|}
\hline & $\begin{array}{c}\text { Normal renal } \\
\text { function }(n=112)\end{array}$ & $\begin{array}{c}\text { Mild renal } \\
\text { dysfunction }(n=349)\end{array}$ & $\begin{array}{c}\text { Moderate renal } \\
\text { dysfunction }(n=150)\end{array}$ & $P$ value \\
\hline Male, n (\%) & $79(70)$ & $243(69)$ & $101(67)$ & .832 \\
\hline Hypertension, n (\%) & $47(41)$ & $124(35)$ & $57(38)$ & .969 \\
\hline Angina CCS II/III, n (\%) & $13(11)$ & $47(13)$ & $15(10)$ & .541 \\
\hline Diabetes, $\mathrm{n}(\%)$ & $66(58)$ & $219(62)$ & $90(60)$ & .711 \\
\hline Smoker, n (\%) & $64(57)$ & $229(65)$ & $111(74)$ & .016 \\
\hline 2-vessel disease, n (\%) & $52(46)$ & $152(43)$ & $49(32)$ & .038 \\
\hline 3-vessel disease, n (\%) & $60(53)$ & $197(56)$ & $101(67)$ & .038 \\
\hline MI, n (\%) & $67(59)$ & $187(53)$ & $87(58)$ & .422 \\
\hline Body mass index $>25, \mathrm{n}(\%)$ & $97(86)$ & $230(65)$ & $81(54)$ & .001 \\
\hline Age, median (years) & 51 & 59 & 67 & $<.05$ \\
\hline Triglycerides, mean $\pm \mathrm{SD}(\mathrm{mg} / \mathrm{dL})$ & $225 \pm 146$ & $192 \pm 113$ & $180 \pm 115$ & $*$ \\
\hline HDL cholesterol, mean $\pm \mathrm{SD}(\mathrm{mg} / \mathrm{dL})$ & $35 \pm 7$ & $37 \pm 10$ & $39 \pm 11$ & $*$ \\
\hline \multicolumn{5}{|l|}{ Treatment } \\
\hline PCI & $40(35)$ & $116(33)$ & $49(32)$ & \\
\hline CABG & $35(31)$ & $122(34)$ & $46(30)$ & .792 \\
\hline MT & $37(33)$ & $111(31)$ & $55(36)$ & \\
\hline
\end{tabular}

Percentages were calculated from a total number in a given renal function group. $C C S$, Canadian Cardiovascular Society; $M I$, myocardial infarction; $H D L$, high-density lipoprotein; $S D$, standard deviation; $P C I$, percutaneous coronary intervention; $C A B G$, coronary artery bypass grafting; $M T$, medical treatment. $* P<.05$ among three groups; after Dunn test, $P$ value $<.05$ of the variable remains significant only between moderate and normal

cholesterol levels (Table 1). We did not observe differences in the prevalence of comorbidities such as hypertension or diabetes mellitus across the range of RF categories. At study entry, 33.4\% were receiving angiotensin-converting enzyme inhibitor (Table 2).

The in-hospital mortality rates were $7.3 \%, 2.51 \%$, and $1.33 \%$, respectively, for the moderate CKD, mild CKD, and normal RF groups $(P=.069)$. Concurrently, the combined event incidence was $12.63 \%, 8.37 \%$, and $12.00 \%$, respectively $(P=.413)$.

\section{Five-Year Clinical Outcome}

The vital status of all randomly assigned patients was ascertained in May 2005. The minimal duration of follow-up was 5 years. No patient was lost to follow-up in all three groups. Table 3 shows the clinical outcomes of RF groups after 5 years of follow-up. Death was observed more frequently in the moderate CKD group than in the other groups $(P<.001)$.

\section{Event-Free Survival}

Figure 1, $A$, shows the combined events, namely incidence of overall mortality, MI, refractory angina necessitat- ing hospitalization, or stroke among the three RF groups across 60 months. The rates of event-free survival were significantly different among patients among the three RF groups $(P=.0013)$, whereas the moderate CKD group presented more combined events than did the mild CKD or normal RF groups $(60 \%, 40 \%$, and $20 \%$, respectively). The pairwise RF group comparisons of the primary end points demonstrated that patients with moderate CKD had 2.1 -fold (95\% CI, 1.309-3.293; $P<.001)$ greater risk of combined events than did those normal RF groups (reference group). On the other hand, no significant difference was found on the risk of primary end points between normal RF and mild RF (95\% CI, 0.846-2.028; $P=.226)$.

\section{Overall Mortality}

There were significant differences among the cumulative overall mortality curves among the three RF groups (Figure $1, B)$. The moderate CKD group had more deaths than did the other two groups $(P=.0007)$. We observed that patients with moderate CKD had a 4.4-fold $(95 \%$ CI, 1.71 $11.54 ; P=.002)$ increased mortality risk compared with the normal RF group (reference). The pairwise RF group

TABLE 2. Medication in use by renal function group

\begin{tabular}{|c|c|c|c|c|}
\hline & Normal renal function & Mild renal dysfunction & Moderate renal dysfunction & $P$ value \\
\hline Beta-blocker, n (\%) & $90(80)$ & $281(82)$ & $121(76)$ & .279 \\
\hline Calcium blocker channel, n (\%) & $66(59)$ & $191(56)$ & $84(53)$ & .676 \\
\hline Antiplatelets, n (\%) & $110(98)$ & $325(95)$ & $151(96)$ & .388 \\
\hline Nitrates, n $(\%)$ & $96(85)$ & $284(83)$ & $132(83)$ & .828 \\
\hline ACE inhibitor, $\mathrm{n}(\%)$ & $40(35)$ & $108(31)$ & $56(35)$ & .580 \\
\hline Statin, n $(\%)$ & $83(74)$ & $209(60)$ & $87(58)$ & .056 \\
\hline Oral antidiabetic, $\mathrm{n}(\%)$ & $14(12)$ & $51(15)$ & $19(12)$ & 618 \\
\hline
\end{tabular}

$A C E$, Angiotensin-converting enzyme. 
TABLE 3. Clinical outcomes by renal function groups after 5 years of follow-up

\begin{tabular}{|c|c|c|c|c|}
\hline & Normal renal function & Mild renal dysfunction & Moderate renal dysfunction & $P$ value \\
\hline New CABG, n (\%) & $12(10)$ & $26(7)$ & $13(8)$ & .547 \\
\hline New PCI, n (\%) & $11(9)$ & $40(11)$ & $19(12)$ & .774 \\
\hline MI, n (\%) & $8(7)$ & $22(6)$ & $15(10)$ & .348 \\
\hline Stroke, n (\%) & $4(3)$ & $11(3)$ & $11(7)$ & .097 \\
\hline Death, n (\%) & $5(4)$ & $33(9)$ & $27(18)$ & .001 \\
\hline
\end{tabular}

$C A B G$, coronary artery bypass grafting; $P C I$, percutaneous coronary intervention; $M I$, myocardial infarction.

comparisons of mortality demonstrate no difference between normal RF versus mild RF (95\% CI, 0.84-5.57; $P=.105)$.

\section{CAD Treatment and CKD}

When we stratified each RF groups based on the CAD treatment, we did not observe significant differences among the three therapeutic strategies regarding the percentage of event-free survival and mortality in moderate or normal RF groups at 5 years of follow-up (Figure 2).

Interestingly, in CKD patients with mild dysfunction, we observed that $\mathrm{CABG}$ treatment presented a statistically higher event-free survival and lower mortality rate than did PCI or MT (Figure 2, $C$ and $D$ ). Treatment and age were the predictors of worse combined events in those patients $(P<.0001$ and $P=.0229$, respectively). However, the received treatment was the only predictor for mortality $(P<.01)$. By using a multivariate logistic regression model and a Cox proportional hazards risk, adjusted for age, sex, body mass index, smoking status, hypertension, MI, total cholesterol, HDL cholesterol, triglycerides, ejection fraction, diabetes, angina status, number of diseased vessels, and treatment allocation, a significant protective effect is observed for CABG compared with MT and PCI treatment in the mild CKD group. The risk of combined events increased 2.9-fold $(95 \%$ CI, 1.68-5.07; $P<.001)$ and 2.8 -fold $(95 \%$ CI, $1.63-4.94 ; P<.001)$ in patients subjected to MT and PCI, respectively, compared with CABG treatment. Additionally, the risk of death was higher in MT patients compared with the CABG group $(\mathrm{RR}=.35 ; 95 \%$ CI, 1.22-9.23; $P=.019$ ), but no difference between PCI-treated patients compared with the CABG group $(\mathrm{RR}=2.7 ; 95 \% \mathrm{CI}, 0.97-7.66 ; P=.056)$ was observed.

\section{DISCUSSION}

Our results confirm that CAD accompanied by CKD has a worse prognosis, regardless of the therapeutic strategy for $\mathrm{CAD}$, when RF is at least mildly impaired. The lowest eGFR group had a 4.5 -fold increased risk of death within 5 years compared with the normal eGFR group. Additionally, our data suggest that the different treatment strategies available for stable CAD may have differential beneficial effects according to the range of eGFR strata. We showed that patients with stable multivessel CAD and CKD, mainly in early stages, had more events when kept in MT over 5 years of follow-up. Of note, CABG patients compared with the PCI or MT patients had a better free-event survival curve and less overall mortality rates only in patients with mild CKD (or stage $2 \mathrm{CKD}$ ). However, among patients with moderate CKD, CABG surgery did not convey a survival benefit over PCI or MT.

Prior studies in high-risk populations, such as those who already have $\mathrm{CAD}$ or who have many risk factors for cardiovascular disease, have suggested that the level of kidney function is a risk factor for cardiovascular disease outcomes. ${ }^{14-18}$ Our results add to a growing body of literature documenting the effects of mild to moderate renal disease on outcomes in patients with CAD. ${ }^{1,19}$

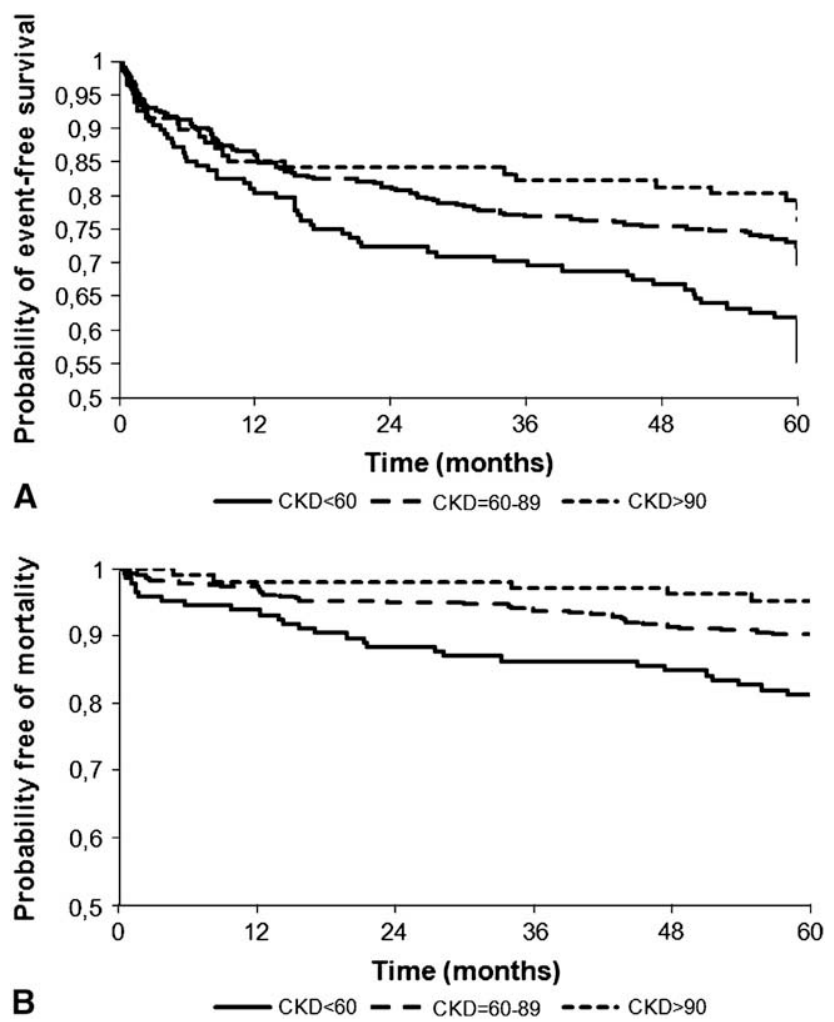

FIGURE 1. A, Kaplan-Meier curves for combined events, namely incidence of overall mortality, myocardial infarction, refractory angina requiring hospitalization, or stroke according to three renal function groups across 60 months. B, Kaplan-Meier curves for overall mortality incidence among the three renal function groups across 60 months. $C K D$, Chronic kidney disease. 

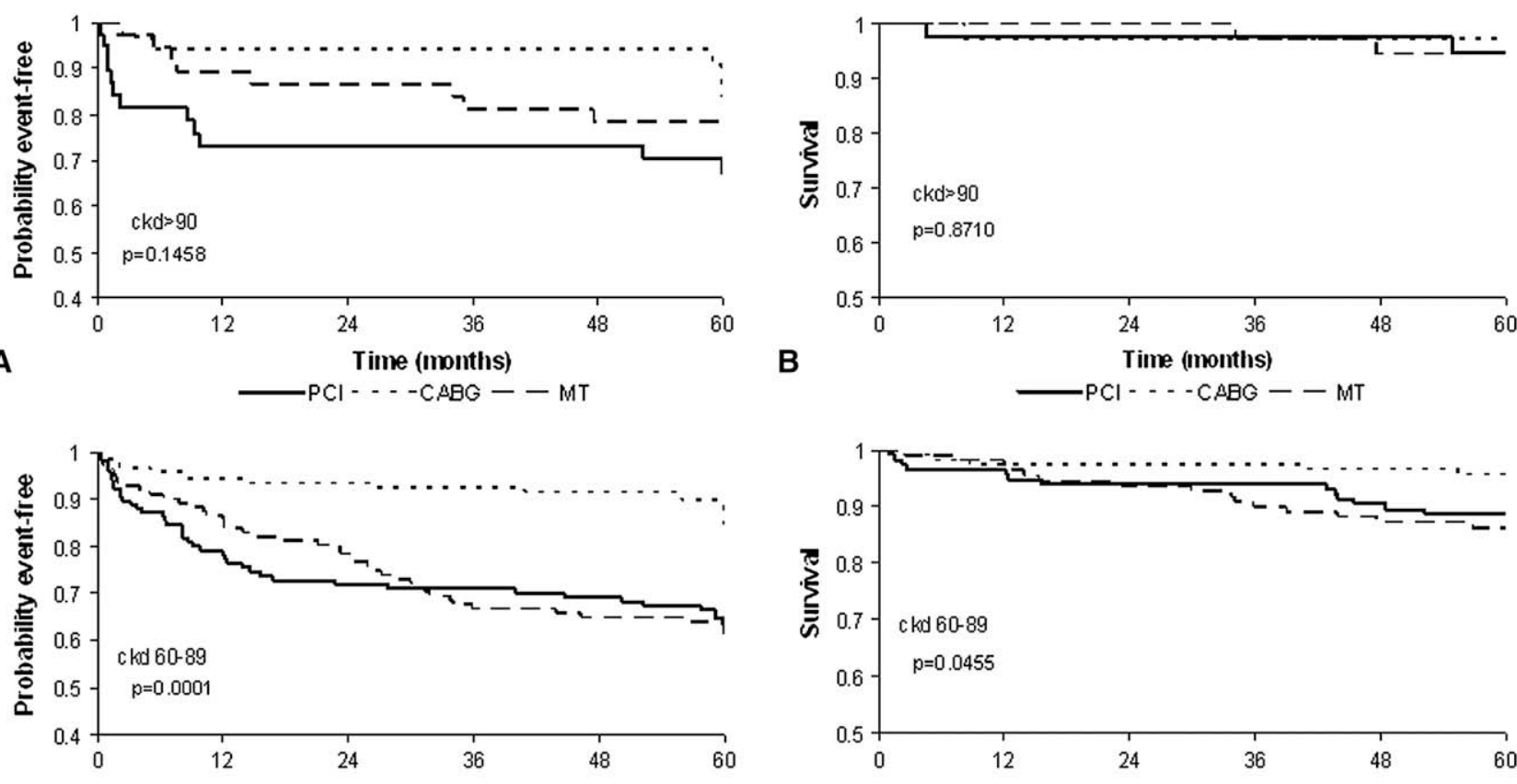

C

Time (months)

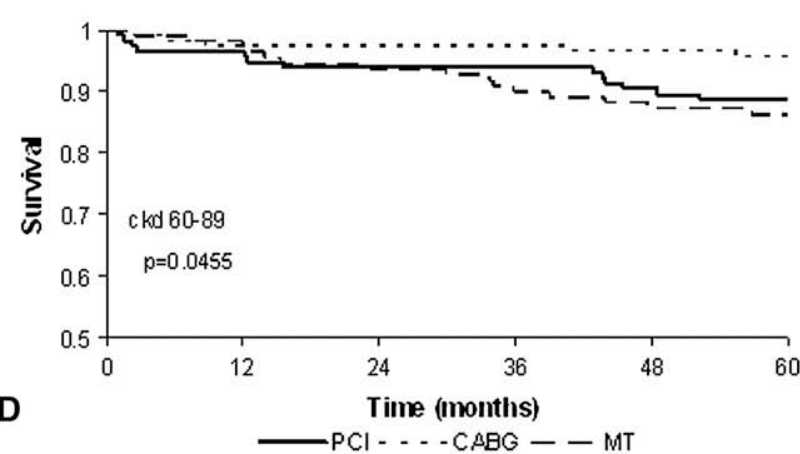

$\longrightarrow \mathrm{PCl}-\ldots \mathrm{CABG}-\mathrm{MT}$
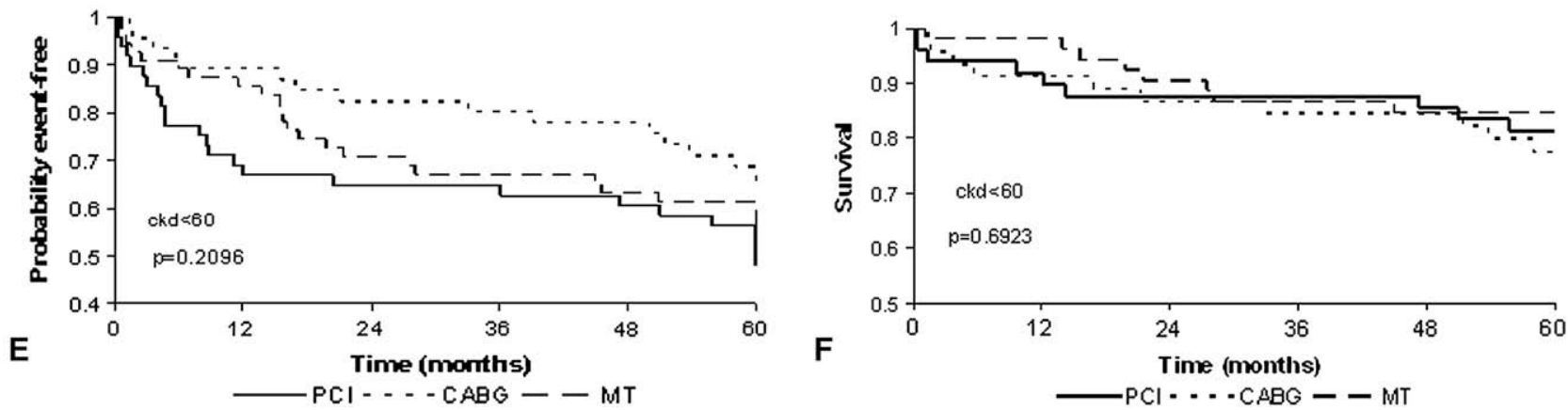

FIGURE 2. Kaplan-Meier curves depicting the incidence of combined end points (A, C, and E) and overall mortality (B, D, and F) according to estimated glomerular filtration rate strata: normal (A, B), mild dysfunction (C, D), and moderate dysfunction (E, F), after 60 months' follow-up. $C K D$, Chronic kidney disease; $C A B G$, coronary artery bypass graft; $M T$, medical therapy; $P C I$, percutaneous coronary intervention.

Our data are consistent with the results of most, but not all, previous studies on the association between minor renal impairment and cardiovascular outcomes. ${ }^{1-5}$ Some of these discrepancies might be limited by insufficient adjustment for traditional risk factors or clinical differences on CAD presentation, use of serum creatinine as the measure of kidney function, and different cutoff points for CKD definition.

Indeed, the mortality and risk of cardiovascular events appears to be directly proportional to decreasing GFR estimates. We could observe in-hospital mortality nearly 6 and 2 times greater in the moderate and mild impairment $\mathrm{RF}$ groups, respectively, than the normal RF group. Conversely, the mortality rate at 5 years' follow-up was nearly 5 and 2 times higher for moderate and mild CKD, respectively, than the normal RF group. Moderate CKD is adversely associated with 5 -year cardiovascular outcomes in patients with multivessel disease, regardless of the therapeutic strategy applied. In our model, moderate CKD (4.4-fold and 2.1-fold increased risk, respectively) and older age (2.5-fold and 1.7-fold increased risk, respectively) were strong and independent predictors of mortality and eventfree survival at 5 years.

Additionaly, we found that patients with moderate dysfunction were older in our study. However, when we analyzed just the group with moderate CKD, we could not observe any known risk factor as a predictor of the worse outcome and higher mortality seen in this group; the studies of others reported that CKD patients have increased age, diabetes, and prevalence of hypertension compared with those with normal RF. ${ }^{2,15}$

In CKD patients, the optimal approach to revascularization has not been determined. Previous reports demonstrated 
a consistent long-term benefit of coronary revascularization over MT alone or percutaneous revascularization with nondrug-eluting stents. ${ }^{7,20-22}$ Regarding PCI treatment, mild CKD is associated with lower procedural success and increased in-hospital complications after PCI. ${ }^{22,23}$ Even if the PCI procedure is successful, cardiovascular events and mortality are increased up to $50 \%$ compared with patients having normal renal function. ${ }^{22}$ Those studies have been limited, however, by the inability to adjust clinical variables, such as severity of CAD and left ventricular dysfunction and other comorbid factors.

More recently, the Results of Prevention of REStenosis with Tranilast and its Outcomes (PRESTO) trial demonstrated an improvement in the results of stent implantation in patients even with renal dysfunction. ${ }^{23}$ They suggested that the results of PCI in CKD are now comparable with results in the general population and that the subsequently increased mortality is not a result of procedural complications or restenosis in the CKD patients, but because of the higher burden of cardiovascular and other comorbid diseases in this particular subpopulation.

In the literature, few studies address the comparison of the three therapeutic strategies to CAD and CKD. The Alberta Provincial Project for Outcomes Assessment in Coronary Heart Disease (APPROACH) ${ }^{24}$ an observational cohort study that compared survival by treatment group (PCI, $\mathrm{MT}$, and $\mathrm{CABG}$ ) for patients with three categories of RF (dialysis-dependent, non-dialysis dependent, and a reference group with serum creatinine less than $2.3 \mathrm{mg} / \mathrm{dL}$ ). In this study, an advantage of an interventionist approach over MT was observed, with noticeable reduction on mortality. The Duke Databank for Cardiovascular Diseases analyzed retrospectively 4584 patients with documented stenosis greater than $75 \%$ of at least one coronary artery. CKD was staged using creatinine clearance derived from the Cockcroft-Gault formula. ${ }^{25}$ They observed that either PCI or CABG was superior to MT in patients with $\mathrm{CKD}$, and in patients with CKD, mainly severe, $\mathrm{CABG}$ was associated with greater mortality reduction than PCI. Although similar to our RF classification, the study design, no randomization, and the different overall number of diseased vessels could potentially lead to different results from the ones provided by our work.

Different from what occurred in the previous studies, mortality was significantly reduced only in patients with mild CKD who underwent CABG compared with MT in our work. After multivariate regression adjustment, we evidenced 2.9-fold and 2.8-fold increased risk of events and 3.4-fold and 2.7-fold increased risk of death in MT and PCI compared with CABG, respectively, and no difference between PCI and MT. It shows the advantage of CABG over the other two forms of therapy in the early stages of CKD. Still, PCI failed to show an advantage over MT regarding the number of deaths.
The major new finding of our study is that in a randomized selected population comparing the three current therapeutic strategies for multivessel stable CAD, the presence of mild CKD, which was observed in $53 \%$ of the patients, modulates in this rather specific group a differential treatment effect on long-term survival and event rates. Surprisingly, the superiority of CABG over either PCI or MT observed in mild CKD was not observed in patients with moderate $\mathrm{CKD}$, in whom a worse prognosis was evident for all three treatment groups.

Interestingly, the mild RF group more closely resembled the moderate RF group than the normal RF group. This demonstrates that discrete variations in renal kinetics can lead to systemic repercussions. Assessment of reinterventional procedures showed that patients with mild CKD and initially randomized to MT had more new CABG procedures and that those randomized to PCI had more new PCI procedures. This suggests that MT should not be encouraged for this group of CKD patients.

Understanding the impact of mild CKD on prognosis and therapeutic strategies of stable multivessel CAD is important, because mild CKD is more than 10 times more prevalent than the end-stage CKD and affects approximately $11 \%$ of the population. ${ }^{5}$ Thus, these findings highlight the clinical importance of mild CKD in the decision-making process of the best therapeutic option for patients with stable multivessel CAD.

In conclusion, renal dysfunction is common in the population with stable multivessel CAD and carries an important predictive role in terms of differential treatment effect on outcomes. A survival and event-free benefit among patients with mild CKD undergoing CABG over PCI or MT was observed. In addition, moderate loss of RF is strongly associated with an increased risk of worse prognosis in CAD, regardless of the therapeutic strategy.

\section{References}

1. Schiffrin EL, Lipman ML, Mann JFE. Chronic kidney disease-effects on the cardiovascular system. Circulation. 2007;116:85-97.

2. Manjunath G, Tighiouart H, Ibrahim H, MacLeod B, Salem DN, Griffith JL, et al. Level of kidney function as a risk factor for atherosclerotic cardiovascular outcomes in the community. J Am Coll Cardiol. 2003;41:47-55.

3. Go AS, Chertow GM, Fan D, McCulloch CE, Hsu C. Chronic kidney disease and the risks of death, cardiovascular events, and hospitalization. N Engl J Med. 2004; 351:1296-305.

4. Fried LF, Shlipak MG, Crump C, Bleyer AJ, Gottdiener JS, Kronmal RA, et al. Renal insufficiency as a predictor of cardiovascular outcomes and mortality in elderly individuals. J Am Coll Cardiol. 2003;41:1364-72.

5. US Renal Data System. USRDS 2005 annual data report. Bethesda (MD): National Institutes of Health, National Institute of Diabetes and Digestive and Kidney Diseases. http://www.usrds.org [accessed 2 December 2006].

6. Gowdak LH, de Paula FJ, César LA, Martinez Filho EE, Ianhez LE, Krieger EM, et al. Screening for significant coronary artery disease in high-risk renal transplant candidates. Coron Artery Dis. 2007;18:553-8.

7. Herzog CA, Littrell K, Arko C, Frederick PD, Blaney M. Clinical characteristics of dialysis patients with acute myocardial infarction in the United States: a collaborative project of the United States Renal Data System and the National Registry of Myocardial Infarction. Circulation. 2007;116:1465-72.

8. Herzog CA, Ma JZ, Collins AJ. Comparative survival of dialysis patients in the United States after coronary angioplasty, coronary artery stenting, and coronary artery bypass surgery and impact of diabetes. Circulation. 2002;106:2207-11. 
9. Aoki J, Ong ATL, Hoye A, Herwerden LA, van Sousa JE, Jatene A, et al. Fiveyear clinical effect or coronary stenting and coronary artery bypass grafting in renal insufficient patients with multivessel coronary artery disease: insights from ARTS trial. EurHeart J. 2005;26:1488-93.

10. Hyre AD, Fox CS, Astor BC, Cohen AJ, Muntner P. The impact of reclassifying moderate $\mathrm{CKD}$ as a coronary heart disease risk equivalent on the number of US adults recommended lipid-lowering treatment. Am J Kidney Dis. 2007;49:37-45.

11. Henry RMA, Kostense PJ, Bos G, Dekker JM, Nijpels G, Heine RJ, et al. Mild renal insufficiency is associated with increased cardiovascular mortality: the Hoorn Study. Kidney Int. 2002;62:1402-7.

12. Hueb W, Lopes NH, Gersh BJ, Soares P, Machado LA, Jatene FB, et al. Five-year follow-up of the Medicine, Angioplasty, or Surgery Study (MASS II): a randomized controlled clinical trial of 3 therapeutic strategies for multivessel coronary artery disease. Circulation. 2007;115:1082-9.

13. Levey AS, Bosch JP, Lewis JB, Greene T, Rogers N, Roth D. A more accurate method to estimate glomerular filtration rate from serum creatinine: a new prediction equation. Modification of Diet in Renal Disease Study Group. Ann Intern Med. 1999;130:461-70.

14. Manjunath G, Tighiouart H, Coresh J, MacLeod B, Salem DN, Griffith JL, et al. Level of kidney function as a risk factor for cardiovascular outcomes in the elderly. Kidney Int. 2003;63:1121-9.

15. Mann JFE, Gerstein HC, Pogue J, Bosch J, Yusuf S. Renal insufficiency as a predictor of cardiovascular outcomes and the impact of ramipril: The HOPE randomized trial. Ann Intern Med. 2001;134:629-36.

16. Dries DL, Exner DV, Domanski MJ, Greenberg B, Stevenson LW. The prognostic implications of renal insufficiency in asymptomatic and symptomatic patients with left ventricular systolic dysfunction. J Am Coll Cardiol. 2000;35:681-9.

17. Anavekar NS, McMurray JJ, Velazquez EJ, Solomon SD, Kober L, Rouleau JL, et al. Relation between renal dysfunction and cardiovascular outcomes after myocardial infarction. N Engl J Med. 2004;351:1285-95.
18. Solomon SD, Rice MM, Jablonski KA, Jose P, Domanski M, Sabatine M, et al. Renal function and effectiveness of angiotensin-converting enzyme inhibitor therapy in patients with chronic stable coronary disease in the prevention of events with ACE inhibition (PEACE) trial. Circulation. 2006;114:26-31.

19. Stam F, van Guldener C, Becker A, Dekker JM, Heine RJ, Bouter LM, et al. Endothelial dysfunction contributes to renal function-associated cardiovascular mortality in a population with mild renal insufficiency: the Hoorn study. $J$ Am Soc Nephrol. 2006;17:537-45.

20. Le Feuvre C, Dambrin G, Helft G, Tabet S, Beygui F, Legendre C, et al. Comparison of clinical outcome following coronary stenting or balloon angioplasty in dialysis versus non-dialysis patients. Am J Cardiol. 2000;85:1365-8.

21. Naidu SS, Selzer F, Jacobs A, Faxon D, Marks DS, Johnston J, et al. Renal insufficiency is an independent predictor of mortality after percutaneous coronary intervention. Am J Cardiol. 2003;92:1160-4.

22. Best PJ, Lennon R, Ting HH, Bell MR, Rihal CS, Holmes DR, et al. The impact of renal insufficiency on clinical outcomes in patients undergoing percutaneous coronary interventions. J Am Coll Cardiol. 2002;39:1113-9.

23. Best PJM, Berger P, Davis BR, Grines CL, Sadeghi M, Williams BA, et al. and PRESTO Investigators. Impact of mild or moderate chronic kidney disease on the frequency of restenosis: results from the PRESTO trial. J Am Coll Cardiol. 2004;44:1786-91.

24. Hemmelgarn BR, Southern D, Culleton BF, Mitchell B, Knudtson ML, Ghali WA. for the Alberta Provincial Project for Outcomes Assessment in Coronary Heart Disease (APPROACH) Investigators. Survival after coronary revascularization among patients with kidney disease. Circulation. 2004;110: 1890-5.

25. Reddan DN, Szczech LA, Tuttle RH, Shaw LK, Jones RH, Schwab SJ, et al Chronic kidney disease, mortality, and treatment strategies among patients with clinically significant coronary artery disease. J Am Soc Nephrol. 2003;14 2373-80. 